\title{
LA PRESENCIA DE LOS MONSTRUOS EN LA PRENSA HISPANICA FINIDIECIOCHESCA
}

\author{
Ma Alejandra Flores de la Flor
}

\section{RESUMEN}

La prensa dieciochesca supone una fuente de información imprescindible para conocer diversos aspectos de la historia en el siglo XVIII. A través de ella, pretendemos conocer cómo era el tratamiento que hacia los monstruos se tenía en la prensa y cuál fue su evolución con respecto a épocas anteriores.

PALABRAS CLAVE: Teratología, prensa, exhibición, hermafroditismo, bicípite.

\section{ABSTRACT}

The eighteenth century press has been an important source of research to know different aspects of History. Through it, we try to know how the press, that represented human thoughts, treated monsters in their pages and how this treatment evolved over the centuries.

KEY WORDS: Teratology, press, exhibition, hermafroditism, bicipite. 


\section{INTRODUCCIÓN}

El término "monstruo" se ha convertido en algo tan global, tan relativo y tan subjetivo $^{1}$ que sería casi una ingenuidad ofrecer una definición exacta. Si analizamos su raíz etimológica, el término procede del latín monstrare que significa enseñar, y sin duda alguna esa idea de enseñar y exhibir es el elemento que más permanencia ha tenido, ya que si algo se ha hecho con el ser monstruoso es exhibirlo, enseñarlo, y darlo a conocer, pues no hay nada que más alimente la morbosidad y la curiosidad humana que la anormalidad que reside en el ser considerado monstruoso. El resto de los elementos que han compuesto las definiciones de "monstruo", ha ido cambiando de la misma manera que se ha transformado la percepción que de éstos se ha tenido a lo largo de las centurias.

El interés por lo monstruoso data de épocas mucho más posteriores de lo que se pudiera en un principio pensar. En culturas tan milenarias como la egipcia o la mochica se pueden hallar representaciones artísticas de seres deformes, de hecho, en ésta última encontramos imágenes de adultos con labios leporinos ${ }^{2}$. En la antigüedad clásica, los monstruos procedían más de la imaginación que de la realidad, pues no eran los seres deformes los que aparecían en los libros sino las razas monstruosas que convirtieron al continente asiático en una tierra de maravillas habitada por cinocéfalos, esciápodos, amazonas, pigmeos, etc. ${ }^{3}$. Menos tolerantes serían con los seres deformes, quienes eran vistos como presagios de hechos futuros, en su mayoría funestos ${ }^{4}$, lo cual suponía, en múltiples ocasiones, la muerte inmediata del mismo, ya fuera por estrangulamiento o por exposición. La Edad Media heredaría el legado clásico gracias a las obras de San Agustín y San Isidoro de Sevilla, y, durante este período, los monstruos estarían muy presentes en la iconografía.

Pero, sin duda alguna, fue en la Edad Moderna cuando esta temática alcanzaría su mayor plenitud, publicándose numerosos tratados de teratologías u obras donde se hacía mención de los seres monstruosos, tales Cosmographie (1554) de Sebastian Münster, Prodigiorum ac Ostentorum Chronicon (1557) de Conrad Lycosthenes, Cosmographie Universelle (1571) de Thevet, la obra imprescindible de Ambroise Paré De Monstres et prodiges (1575) e Historias prodigiosas (traducción española, 1603) de Pierre Boaistuau, perviviendo esta temática en el siglo XVII con los tratados de Aldrovandi o Kaspar Schenk. En España, podríamos citar Jardín de flores curiosas (1575) de Antonio de Torquemada, Curiosa y oculta filosofía (1643) de Eusebio Nieremberg, El ente dilucidado (1676) de Antonio de Fuentelapeña y Desvios de la naturaleza o tratado del origen de los monstruos (1695) de José Rivilla y Bonet. La Edad Moderna, por tanto, convierte al monstruo en objeto de interés general, no sólo para curiosos sino para

1 Vid. KAPPLER, Cl.: Monstruos, demonios y maravillas a fines de la Edad Media, Madrid, Akal, 1986. 2 SALAMANCA BALLESTEROS, A.: Monstruos, ostentos y hermafroditas, Granada, ed. Universidad de Granada, 2007, p. 49.

3 Sobre la visión griega del mundo oriental: GÓMEZ ESPELOSÍN, F. J.: El descubrimiento del mundo. Geografía y viajeros en la antigua Grecia, Madrid, ediciones Akal, 2000. Y, por supuesto el clásico de WITTKOWER R.: "Marvels of the East: a study in the history of monsters", Journal of the Warburg and Courtauld Institutes, 5, 1942, pp. 159-197. Traducción española, "Maravillas de Oriente: Estudio sobre la historia de los monstruos", Sobre la arquitectura en la edad del Humanismo. Ensayos y escritos, Barcelona, Editorial Gustavo Gili, 1979. También, FRIEDMAN, John Block: The monstrous races in medieval art and thought, Cambridge Mass, 1981.

4 El precursor de esta idea fue Cicerón con su obra Sobre la adivinación. 
médicos, religiosos, juristas, exploradores y conquistadores ${ }^{5}$ e incluso el rey y su corte mostraban interés por ellos, mandando traer estas criaturas para poder admirarlas ${ }^{6}$. Por tales motivos, en cualquier obra teratológica que se precie se muestra un gran interés por satisfacer el conocimiento de campos tan dispares, y no hay monstruo que se trate del que no se hable de su constitución médica y de lo que suponía su situación jurídica y religiosa (en el caso de los bicípites, su bautismo daba lugar a todo tipo de análisis religiosos). Durante mucho tiempo el monstruo fue una incógnita para un conocimiento humano que se hallaba en la Edad Moderna en plena evolución, y en el siglo XVIII la resolución de esa incógnita supuso que fuese visto desde una perspectiva distinta, menos supersticiosa y más racional y científica, cambio que fue magistralmente analizado en su momento en la obra clásica de Lorraine Daston y Katherine Park ${ }^{7}$.

En este trabajo pretendemos ver ese cambio de percepción a través de la prensa española de finales del siglo XVIII y principios del XIX. En los últimos años, se han hecho estudios teratológicos abordados desde diversos campos como la medicina o la literatura, sin embargo, la presencia de esta temática en la prensa española ha pasado desapercibida incluso en estudios clásicos como el de Paul Guinard ${ }^{8}$, por lo que con el fin de llenar ese vacío ofrecemos una visión global de los cambios, pero también de las continuidades que a lo largo del siglo XVIII se producen en cuanto a la percepción de lo monstruoso, resaltando la función de la prensa como una fuente más para el estudio de la teratología.

\section{LOS MONSTRUOS EN LA PRENSA}

Si a lo largo de los siglos XVI y XVII fueron las relaciones de sucesos y los avisos las principales fuentes informativas con respecto a los monstruos (con excepción de los libros de viajes y las obras propiamente teratológicas), con la incursión de mercurios y gacetas a lo largo del XVII y el surgimiento de una verdadera prensa en el siglo XVIII, se produce un relevo. Es en ese momento en el que los periódicos se convierten en el principal medio informativo, no sólo en cuestiones políticas, económicas o literarias, sino también de hechos memorables como el nacimiento de niños monstruosos.

Obviamente, no se trataba de una prensa de ámbito nacional tal y como la conocemos hoy día, sino de una prensa que surge en las principales ciudades como Madrid, Barcelona, Sevilla, Cádiz, Valencia, o Salamanca, para luego ir extendiéndose por toda la geografía española. Es un tipo de rotativo, además, en el que los monstruos tienen lugar porque su contenido era variado y plural, de hecho, en el prólogo de la Gazeta de México se dejaba entrever que uno de sus objetivos era el de publicar artículos que tra-

5 Estos últimos no dudaban en recurrir a la existencia de monstruos en el Nuevo Mundo para conseguir la financiación de grandes señores para su empresa, un buen ejemplo lo encontramos en Sir Walter Raleigh o Domingo Vera, ambos interesados en encontrar "El Dorado". GARCÍA ARRANZ, Julio: "La imagen del monstruo como instrumento político religioso" en M. P. Díaz Barrados (coord.): Las edades de la mirada, Universidad de Extremadura, Instituto Ciencias de la Educación, 1996, pp. 129-140.

6 Numerosos textos de la época hacen mención de la presencia de monstruos en la corte: "porque con ocasión de un desacierto de la naturaleza, que estos días pasados ha admirado esta corte, de dos cuerpos humanos asidos entre si...". NIEREMBERG, Eusebio: Curiosa y oculta filosofía, Alcalá, Imprenta de María Fernandez, 1649. Libro III. Cap. I Fol. 63.

7 DASTON, Lorraine, y PARK, Katherine: Wonders and the order of nature, Nueva York, Zone Books, 2001.

8 GUINARD, P., La presse espagnole de 1737 à 1791, París, 1973. 
tasen con toda exactitud de los distintos puntos geográficos del país y de "curiosidades de su historia natural", por lo que, cumpliendo con su propósito, poco a poco el periódico empezó a publicar noticias sobre seres extraordinarios ${ }^{9}$. Sin embargo, aunque éstos aparecieran en publicaciones como Diario de Madrid, El correo mercantil de España y sus Indias, El Correo de Madrid o Mercurio de España, por citar algunos nombres, el talante con el que se informa era radicalmente distinto al de las relaciones de sucesos. El miedo al castigo divino y las interpretaciones teratoscópicas e, incluso, las manipulaciones políticas y religiosas ${ }^{10}$, desaparecieron en pos de un tono estrictamente científico e informativo donde primaban los datos del quién, del dónde, del cuándo y del cómo. Así, por tanto, las introducciones como ésta: "En Lisboa [...] quizo la magestad de Dios (quiça para pronostico de muchos castigos que se nos aguardan, en pena de tantos y tan graves pecados con que los hombres a su hacedor tienen offendido è irritado, ò quiça para pronostico de algunos bienes, que ha de hazer a la Christiandad)" ${ }^{11}$, serían sustituidas por este otro tipo: "Francisca Duval, muger de un labrador del Lugar de Lambale, Parroquia de Fleunec en Bretaña, de edad de treinta y cinco años, y que había parido felizmente à varios hijos, à los nueve meses de preñada se sintió con dolores de parto. Despues de muchos esfuerzos vió la comadre que la cabeza salía con mucha dificultad...pero al fin salió" ${ }^{12}$.

El tono no era sólo radicalmente distinto, sino también el tratamiento de la noticia. Pues, mientras en las relaciones de sucesos las descripciones eran vagas y, en ocasiones, inexactas (fruto de la imaginación del autor en algunos casos), en los periódicos primaban los relatos con un marcado talante médico y anatómico y con gran profusión de datos concretos. Así, en relación al niño que dio a luz Francisca Duval, se proporciona un retrato verbal de la apariencia externa del niño (el cual poseía dos cabezas bien formadas), así como de su conformación interna y de su esqueleto. Éstos serían muy comunes incluso para los casos de deformidad simple tales como el siguiente: “...una niña nacida en Orleans, de tres meses y medio, sin las extremidades thorácicas y abdominales. No tiene mas en el muñon del hombro izquierdo que la extremidad clavicular

\footnotetext{
9 ZÁRATE, Verónica y FLORES, Eduardo: "Lo monstruoso en Nueva España, o la percepción de una naturaleza excepcional" en E. Stols, W. Thomas y J. Verbeckmoes: Naturalia, mirabilia et monstrosa en los Imperios Ibéricos siglos XV-XIX, Universidad de Lovaina, 2007, p. 261. En este mismo trabajo ambos autores resaltan que las noticias de monstruos en la Gazeta de Mexico fueron muy numerosas entre 1784-1787 pero que posteriormente, y debido quizás a las quejas de los lectores, disminuyeron considerablemente, o también debido a la disminución de la cantidad de portentos, p. 272.

10 A pesar de que los monstruos no eran usados como medio para desacreditar políticamente o religiosamente como en su día hizo Lutero con el famoso Asno-papa, sí que es cierto que la palabra "monstruo" sería usada en numerosas ocasiones para referirse a Napoleón y a los franceses durante la Guerra de la Independencia española tal y como se puede apreciar en el siguiente texto: "Pueblos españoles: La Francia toda culpable y criminal, guiada por un monstruo feroz y sanguinario, rival de la divinidad, y enemigo de los hombres..." Correo político y literario de Salamanca, 1 de Octubre de 1808. Igualmente se utilizaría para descalificar algunas actitudes tales como el egoísmo, la ludopatía (el ludópata), la mentira, la envidia, o la intolerancia. "Un egoísta es el mayor monstruo de la sociedad" Diario de Madrid, 26 de septiembre de 1795. Asimismo, será muy frecuente encontrar obras teatrales tituladas: "El monstruo de la fortuna" o "El mayor monstruo los zelos" de Calderón de la Barca

11 Relación verdadera de un monstruoso niño, que en la Ciudad de Lisboa nació a 14 del mes de Abril de 1628, la cual en una carta ha embiado de Madrid Sebastian de Grajal es Ginoves a un Mercader desta ciudad, junto con la efigie verdadera de dicho monstruo, la cual se saco de una que embiaron à la Magestad del Rey nuestro señor. Relación extraída de ETTINGHAUSEN, H. (ed.): Noticias del siglo XVII, relaciones españolas de sucesos naturales y sobrenaturales, Barcelona, Pulvill Libros, 1995.

12 Espíritu de los mejores diarios literarios que se publican en Europa. $\mathrm{N}^{\circ}$ 173. 23 de Marzo de 1789, p 1027.
} 
del humero, de una pulgada de largo, y presenta un gran movimiento por medio de la articulación escapulo-humoral que está muy intacta, y de los músculos que se unen a este muñon"13.

Cabe preguntarse a qué se debe ese cambio en el tratamiento de las noticias monstruosas. La respuesta habría que buscarla en el tipo de lector, por cuanto las relaciones de sucesos siempre fueron dirigidas a un amplio público y su precio era menor por lo que casi cualquier persona podía comprarlas y compartirlas entre sus familiares y amistades cercanas, o saber su contenido simplemente oyendo como lo contaban buhoneros o caminantes que hacían el papel de mediadores. Los periódicos, sin embargo, estaban dirigidos a una minoría que gozaba de una buena educación y que era capaz de comprender un lenguaje más elaborado, nos referimos a nobles, clérigos, miembros de la burocracia real, representantes de la clase media tales como médicos, abogados, o profesores, y, en menor medida, comerciantes ${ }^{14}$. Gentes en las cuales las supersticiones, supuestamente, no tenían cabida, pues se consideraban algo propio del vulgo ignorante y analfabeto, lo que no hace más que reflejar la dicotomía, típicamente dieciochesca, entre una cosmovisión dominada por lo sobrenatural, lo mágico y lo irracional, y otra presuntamente más científica y racionalista ${ }^{15}$. Por tanto, la manera de informar sobre los seres monstruosos tenía como fin despertar el interés o la curiosidad científica y médica más que provocar una reacción supersticiosa ante el poder de Dios o el futuro incierto.

Sin embargo, a pesar de este halo de cientifismo no faltarían los anuncios de exhibición de monstruos que ya fueron comunes en los siglos pasados ${ }^{16}$. Esta permanencia en querer exhibir las deformidades físicas, no sólo demuestra que la actitud general del hombre hacia lo anormal no había cambiado en gran medida, pues la búsqueda de lo morboso y los beneficios económicos llegaban a primar en determinadas ocasiones más que el interés científico, sino que además se demuestra el hecho de que la exhibición era el medio de vida más rentable ${ }^{17}$. Así, por tanto, no era raro encontrarse anuncios como éstos: "Desde oy dia 13 del corriente se dexarà vèr el Gigante, que ha llegado a esta

13 Minerva o El Revisor General. Tomo VII. 1807, pp. 45 y ss.

14 Para el estudio del público de la prensa recomendamos: LARRIBA, Elisabel: "El publico de la prensa" en V. Infantes de Miguel, F. López y J. F. Botrel (coord.): Historia de la edición y la lectura en España 1475-1914, Fundación Germán Sánchez Rupérez, 2003, pp. 463-470. Y, naturalmente, su obra clásica, Le public de la presse en Espagne a la fin du XVIIIe siécle, París, 1998. En el caso de la Gazeta de Mexico, sin embargo, Zárate y Flores explican que el lector de la misma no tenía ni porqué ser letrado pues, en ocasiones, las imágenes divulgadas eran tan elocuentes que no necesitaban de discurso escrito. ZÁRATE, Verónica y FLORES, Eduardo: op. cit., p. 273. Sin embargo, conviene puntualizar que a pesar de que los lectores de la prensa fueran minoritarios en comparación con los de las relaciones de sucesos, no quiere decir que las noticias no llegaran al resto de la población bien mediante la lectura en voz alta o bien mediante la propia circulación de noticias -lo que vulgarmente se conoce como boca a boca-.

15 Las actitudes dieciochescas ante la brujería constituyen el ejemplo clásico de esta dicotomía. Vid. PORTER, Roy: "Witchcraft and magic in Enlightenment, Romantic and Liberal thought", en M. Gijswijt-Hofstra, B. P. Levack, y R. Porter: The Athlone History of Witchcraft and magic in Europe, vol. 5: The Eighteenth and Ninenteenth centuries, Londres, 1999. Para España, CAMPAIGNE, Fabián Alejandro, Homo Catholicus. Homo Superstitiosus. El discurso antisupersticioso en la España de los siglos XV a XVIII, Buenos Aires, Universidad, 2002, pp. 630-631, que incide en la misma idea.

16 Un planteamiento general de la exhibición de lo monstruoso en el siglo XVIII, en HAGNER, Michael: "Utilidad científica y exhibición pública de monstruosidades en la época de la Ilustración”, en Monstruos y seres imaginarios en la Biblioteca Nacional, Madrid, Algete, 2000.

17 Salamanca Ballesteros explica que la exhibición de los monstruos era la mejor forma de sobrevivir frente a la mendicidad, la marginación o el propio infanticidio, asimismo estas exhibiciones proporcionaba entretenimiento al público y auto-enriquecimiento o enriquecimiento a la persona que lo exhibía. SALAMANCA BALLESTEROS, Alberto: op. cit., p. 83 
Corte, su casa, que hace esquina á la calle Valverde, frente de los Basilios, se pagarà diez reales de vellón por cada uno que quisiere verle. La hora será, para este fin, por la mañana desde las diez hasta la una, y por la tarde desde las tres hasta las ocho"18.

Queda claro al leer este anuncio que no es el interés científico lo que movería al lector para visitar al gigante, sino más bien la curiosidad y la morbosidad por ver a un ser de una estatura monstruosa por lo anormal. La falta de interés científico se observa en el lenguaje llano del anuncio -por tanto, comprensible incluso para un lector con escasa formación cultural-, la carencia de una descripción científica/médica/anatómica y la aparición de datos como los horarios de visita y el precio, por lo que podemos deducir que se buscaba más una atracción de feria que una exhibición científica. Un caso similar es el de este otro gigante traído a Madrid: "Aquí se habla mucho de un hombre extrangero acaponado y agigantado, que como otras 300. Maulas, se metió en Madrid y le conduce, como en espectáculo, un Charlatan saltimbanco; no dexandole ver, sino al que paga una peseta"19.

En ocasiones, la exhibición no suponía la demostración del monstruo en sí, es decir en vivo, sino tan sólo de su imagen: "Retrato de un monstruo humano que ha nacido en un pequeño lugar de los estados del Rey de Cerdeña: carece de manos y de pies; del principio del muslo le sale un dedo con el qual toca un tambor, y escribe: con la boca enebra una aguja y hace otras habilidades. Se hallará en los puestos del Diario de la Plazuela de Sto. Domingo [...] su precio, 4 quartos" ${ }^{20}$. De esta manera, también el periódico servía como instrumento de exhibición, hasta tal punto de que ni siquiera se proporcionará información escrita, sino únicamente la imagen, tal y como se puede observar en el Diario de Valencia donde se daba noticia del nacimiento de una niña bicípite informando solo del lugar y fecha de nacimiento y con la imagen como protagonista.

Del mismo modo que seguía vivo el carácter exhibicionista de los monstruos, también permanecerían vivos otros conceptos y creencias de épocas pasadas como el de la influencia de la imaginación materna. La permanencia de éstas puede demostrarse en una carta publicada en el Espíritu de los mejores diarios literarios... donde un hombre relataba un hecho que había visto con sus propios ojos. En esa misma carta, el autor explicaba como la creencia en la influencia materna se había diluido en el siglo XVIII a través de estas pocas palabras: "siempre había creido como vmds. Que lo que llamamos antojo o manchas de nacimiento eran unos meros juegos de la naturaleza, cuya existencia a la verdad no se podía negar, pero que su causa era muy incierta"21.

Sin embargo, a pesar del predominio de la razón o del abandono de la superstición, el autor de la carta no dejaba de mostrarse asombrado del hecho del que fue testigo. Así, cuenta, que estando en Roma había conocido a una mujer embarazada que, antojada de beber vino, no lo había pedido por vergüenza. Según el autor, la propia mujer le había contado esa misma tarde sus antojos y su temor de que el niño naciera marcado, a lo que el autor respondió con burlas al respecto ${ }^{22}$. Tal fue la sorpresa de éste al descubrir,

18 Diario noticioso, curioso-erudito, y comercial público y económico. $\mathrm{n}^{\circ} 11.13$ de Octubre de 1758, p. 348. 19 Correo Literario de la Europa, en la que se da noticia de los libros nuevos, de las invenciones, y adelantamientos... N $\mathrm{N}^{\circ}$ 54. 20 de Junio de 1782, p. 369.

20 Diario de Madrid. N ${ }^{\circ} 113.22$ de Abril de 1788. P. 443.

21 Espíritu de los mejores diarios literarios que se publican en Europa, $\mathrm{n}^{\circ}$ 182. 24 de Mayo de 1789, pp. 85-86.

22 “Como yo era un poco incrédulo en este punto, me chanceé bastante con esta mujer...”. Ibídem. 
al paso de los meses, que la mujer había estado en lo cierto pues el niño había nacido con una mancha en el párpado derecho del tamaño de una pieza de dos reales de vellón, que simbolizaban el precio del vino.

Otro ejemplo del poder de la imaginación sería recogido en el Memorial literario donde el autor de la relación relataba dos casos. El primero de ellos era el de una mujer que poseía todos sus "miembros dislocados ó quebrantados por los mismo parages que lo están los de un reo que ha sufrido el suplicio de la rueda" ${ }^{23}$, debido a que su madre, estado embarazada, había cumplido el antojo de presenciar una ejecución. Y el segundo ejemplo es el de una mujer que había dado a luz a un niño con apariencia similar al de un mono vestido, debido a que ésta había visto en la feria a uno vestido de manera ridícula, cuya imagen se le había quedado grabada en la mente. Sin embargo, el autor de esta relación, al contrario que el anterior, se mostraría reticente en creer este tipo de efectos, afirmando que los consideraba "juguetes de la naturaleza muy distantes de la causa á que se atribuye" y que esta creencia era fruto de la aprensión de las personas que a "la más pequeña relación que imagine hallar entre sus sensaciones y la figura del niño, es suficiente para que describa estas sensaciones con un entusiasmo y unas circunstancias que las dan aun mas analogía con el efecto"24.

Un aspecto importante a destacar sobre las noticias de monstruos en los periódicos, es la veracidad. El nivel de ésta en las publicaciones diarias era mayor que en las relaciones de sucesos, las cuales, en ocasiones, contenían pocos datos o bien erróneos debido a que las noticias plasmadas en ellas solían provenir de rumores, historias de oídas o probablemente de la invención de una mente imaginativa ${ }^{25}$. En los periódicos, la veracidad se demuestra de muchas maneras: proporcionando fecha exacta, nombre de los padres de la criatura que había nacido con deformidad, lugar de nacimiento - no sólo la ciudad sino que, en ocasiones, también la calle-, y se solía indicar la presencia de médicos (que en el siglo XVIII han sustituido a los clérigos como garantes de la verdad $)^{26}$ y autoridades que habían asistido para testimoniar la certeza del hecho. Así, por ejemplo, nadie puede poner en duda la noticia leída en la Gazeta de México el 24 de febrero de 1789 donde se ofrecía una copia de la certificación auténtica del nacimiento de un niño monstruoso, describiéndose con todo tipo de detalle el proceso de identificación y certificación del mencionado monstruo: "Certifico en testimonio de la verdad, que habiendo sabido el Sr. D. Pedro Antonio de Septien, Regidor Decano, Alferez Real, Procurador mayor general de esta Ciudad, y Comisionado por su Ilustre Ayuntamiento para la colección de noticias interesantes y conducentes al mayor lustre y utilidad de la Gazeta de Mexico, que en la posada de Doña Mariana Josefa de Castañeda de esta vecindad, viuda de D. Luis Mier, se halla un niño monstruoso [...] puestosele por nombre Joseph Maria, á el qual mandó dicho Señor comisionado descubrir enteramente y en

23 Memorial literario. $\mathrm{N}^{\circ}$ 54, p. 310

24 Ibídem, p. 311.

25 Para ampliar el estudio de los monstruos en las Relaciones de sucesos remitimos a las siguientes obras: ETTINGHAUSEN, H. (ed.): op. cit.; REDONDO, A.: "Los prodigios en las relaciones de sucesos de los siglos XVI y XVII", en Las relaciones de sucesos en España (1500-1750): actas del primer coloquio internacional, Universidad de Alcalá de Henares, 1996; GARCÍA ARRANZ, J.: "Las relaciones de monstruos en el contexto de la teratología ilustrada de la Edad Moderna", en La fiesta. Actas del II Seminario de Relaciones de Sucesos, La Coruña, Sociedad de Cultura Valle Inclán, 1999, pp. 136-137.

26 Sobre esta medicalización de la veracidad, remitimos a FOUCAULT, Michel: El nacimiento de la clínica. Una arqueología de la mirada médica (1966), Madrid, Siglo XXI, 2007. 
este estado prolijamente reconocido e inspeccionado por el Br. D. Francisco de Inza, Médico examinado y aprobado, y por el Maestro D. Joseph de Sotomayor, Cirujano también aprobado..."27.

Nótese que la presencia del médico -o médicos, en esta noticia en particular- no es por azar. Su testimonio otorgaba a la noticia un interés científico pero también ofrecía garantías de que el monstruo era verdadero al cien por cien y no una estafa planeada por los padres ni tampoco un relato inventado por el periodista, el autor o el editor. La presencia de los médicos y/o cirujanos sería frecuente en las noticias sobre nacimientos de niños con deformidades, tal y como podemos leer en esta otra noticia: "La muger de N. Jouvenot [...] de buena constitución y preñada de 7 meses, se sintió con dolores de parto, $[. .$.$] y à poco tiempo terminó el Parto con felicidad, cuya producción fue un niño$ monstruoso [...] con permiso de los parientes llevò [la comadre] el Monstruo à su casa, y llamò al nombrado cirujano para que examinase su construcción, y haviendolo hecho expusò la relación siguiente, que contiene lo que notò de singular, y extraordinario" 28 .

No sólo la aparición de los facultativos era constante, sino también la de las principales autoridades de la ciudad como podían ser los curas, los alcaldes, los escribanos o cualquier personalidad notable: "Habiendo dado a luz Josepha López [...] un monstruo biforme en la tarde de 28 de Junio, y noticioso de ello D. Saturnino Andrés Diez Guilarte, Cura Beneficiado de aquella parroquia, pasó a cerciorarse del suceso con asistencia del Alcalde ordinario Manuel Martinez Fuentes, y del Escribano Real y del número de la misma villa Pedro Garcia Manrique [...] dispuso con acuerdo de los demás individuos de dicha Junta, y el consentimiento de los padres, remitirlo en la misma noche con el oportuno testimonio de todo al Conde de Castañeda de los Lamos, Procurador general de dicha ciudad de Burgos, el qual lo hizo reconocer por el Catedrático de anatomía de aquel Real colegio de la facultad reunida D. Pablo Capdevilla..."29.

En otras ocasiones, sin embargo, la presencia de vecinos como testigos del acto bastaba para ofrecer garantías de la veracidad del hecho: "Tenía este niño tres lenguas muy perfectas, con la distinción de que la superior le sobresalía de la boca y ocupando el labio de arriba (que estaba como partido) venia a rematar pegada à la nariz como punta de pico de Águila [...] Fueron testigos de esta monstruosidad varios vecinos del pueblo..." ${ }^{30}$.

\section{TIPOLOGÍA DE LO MONSTRUOSO}

La tipología de los monstruos aparecidos en los periódicos es bastante variada y, en cierta manera, similar a los que aparecían en las relaciones de sucesos y avisos. Así, por ejemplo, encontramos animales monstruosos, monstruos bicorpóreos y bicípites, hermafroditas, gigantes y enanos, partos múltiples, etc. Sin embargo, nos parece interesante detenernos en cada uno de los tipos de monstruosidades que más se repetían y ver cómo eran tratados.

27 Gazeta de México. № 26. 24 de febrero de 1789, pp. 253 y ss.

28 Diario curioso, histórico, erudito, comercial, civil y económico. $\mathrm{N}^{\circ} 58.3$ de Agosto de 1772.

29 Mercurio de España. Julio de 1800, pp. 299 y ss.

30 Gazeta de México. № 31. 19 de Mayo de 1789, pp. 306-307. 


\section{Animales Monstruosos}

Dentro de la tipología de los monstruos en los periódicos, los animales monstruosos eran los que menos credibilidad poseían. Y es que, en ocasiones, no sólo su forma parecía fruto de la imaginación, sino que también sus avistamientos y el propio ser en sí iban envueltos en leyendas poco o nada creíbles. Su tipología es muy amplia y podemos encontrar desde el simple animal que nacía con alguna anormalidad hasta aquél que parecía fruto más de la imaginación que de la realidad. Dentro del primer grupo, era común encontrarse noticias de animales que nacían con miembros duplicados tales como la cabeza, las patas o el rabo. Así por ejemplo, en la Gazeta del México del año 1792 nos hallamos con la noticia de un cordero monstruoso: “... se hallaba en estos días un Corderito muerto que traxeron del Valle grande, el que tenía quatro pies, quatro manos, una cabeza y dos lenguas, y encima del pescuezo como à modo de calavera, de cuya Casa lo anduvieron enseñando" 31 .

En ocasiones, la monstruosidad iba más allá de los miembros duplicados y daba lugar a monstruos verdaderamente esperpénticos tal y como el que recogía el Semanario económico: “...era una ternera cuya cabeza tenia la mas singular extructura. [...] la frente mas ancha de lo regular figuraba dos: solo tenia dos orejas, pero tres ojos uno à cada lado muy hermoso, y enmedio de la frente tenia el tercero algo mas pequeño que los otros dos, pero bien rasgado. Esta grande cabeza tenía dos quixadas, una en cada lado, separadas la una de las otras tres à quatro pulgadas" ${ }^{\prime 2}$.

Junto a esta clase de animales monstruosos serían muy comunes los monstruos marinos que habían sido vistos, en su mayoría, por marineros durante largas travesías a tierras exóticas. Entre el más raro y monstruoso cabe destacar el que recoge el Diario de Madrid y que se halló en la costa de Francia: “.... a fines del mes de Abril próximo pasado, entre las rocas de la bahía de Pouliguen [...] un monstruo marino tan espantoso como extraño. Tenia 9 pies de largo, y su grueso era como la de un becerro. La cabeza, mucho mayor que la de un toro, era de la misma forma, y también las orejas, en ella había dos astas muy largas, la una derecha y la otra retorcida como la de los carneros. De en medio de ellas salía una excrecencia carnosa y recortada a modo de corona, semejante a la cresta de los gallos, y debaxo un solo ojo..." ${ }^{33}$. La aparición de este animal sería acompañado de fuertes bramidos y envuelto con cierto halo de superstición cuando el periodista indica que deja en manos del lector cualquier tipo de interpretación, como dejando entrever cierto temor o superstición por parte del autor.

Otros monstruos marinos serían menos desconocidos, de hecho gozaban hasta de nombres como ocurría con los monstruos Emboa, Espanlones o Schark. El primero de ellos era un monstruo marino hallado en las costas de Loango, en la actual Angola, al que los nativos de aquellas tierras solían respetar durante la pesca. En su lengua, Emboa significaba perro y durante la caza temían herirle, sin embargo, en la noticia no se espe-

31 Gazeta de México, № 8. 24 de Abril de 1792. P. 73. Para ampliar el conocimiento de adquisiciones de rarezas en el Nuevo Mundo recomendamos: DE VOS, Paula: "The rare, the singular, and the Extraordinary: Natural History and the collection of curiosities in the Spanish Empire", en D. Bleichmar, P. De Vos, K. Huffine y K. Sheehan (eds.): Science in the Spanish and Portuguese Empires, 1500-1800, Standford University Press, 2009, pp. 271-289. 
cifica el porqué ${ }^{34}$. El segundo era un monstruo marino descrito como un animal con una "cabeza armada de un huesso muy largo pero liso y puntiagudo, que parece al cuerno fabuloso del Unicornio"35. Y al contrario de lo que ocurría con el Emboa, en la noticia sí se especifica porqué era temido y es que se pensaba que este monstruo era capaz de penetrar una embarcación y hacer una boca de agua. Este hecho convertía al Espanlones muy similar al monstruo que recoge El correo mercantil de España y sus Indias llamado Golu. Este monstruo se encontraba en la exótica isla de Java y era descrito como "un pez espada que atraviesa los navios con un solo golpe de su espada" 36 . Por último, el Schark era un monstruo marino que se hallaba en abundancia en los trópicos, y era descrito como animal con "los ojos pequeños à proporción del cuerpo y que son redondos, y muy inflamados. Los huessos de su quixada tienen un resorte tan singular, que puede abrir la boca al gruesso de su presa" ${ }^{37}$.

Pero, sin duda alguna, sería el Monstruo de Jerusalén el que más expectación crearía. La noticia de su existencia sería recogida en la Gazeta de México del 24 de Marzo de 1789, y, al parecer, se dio a conocer por la cantidad de estragos que había provocado en seres humanos y ganado que habían aparecido despedazados en la mencionada Sierra de Jerusalén. El susodicho monstruo fue descubierto por un "caminante" que advirtió que otro que iba más adelantado que él era atacado por un "animal monstruoso", destrozándolo en un instante. Totalmente asustado, se dirigió a la población más cercana donde relató lo sucedido provocando la reacción del pueblo que se dirigió a darle caza. El monstruo es descrito en la noticia como si de una quimera se tratase, acudiendo a la conocida técnica del jigsaw o puzzle, tan recurrente en la Modernidad para describir cualquier especie desconocida ${ }^{38}$ : "Este horrendo monstruo era de la magnitud de un Caballo; pero su espantosa cabeza á especie de la de un León; en ella tiene dos astas á modo de las de un Buey: la punta de la nariz como un gran pico de Aguila; los dientes de un gran León; colmillo de Javalí de à palmo y medio de largo: las orejas muy caídas; quatro tetas como Bacas; el pecho poblado de pelo, los pies con garras muy largas, la cola de un Basilisco sobre seis palmos de largo, y la punta como flecha, del espinazo le salen seis espolones de Gallo, pero mucho mayores sobre todo el anca abaxo..." 39 .

Por tanto, no había animal que no estuviese representado en el Monstruo de Jerusalén: caballo, león, águila, vaca, jabalí, e incluso criaturas mitológicas como el Basilisco. A toda esta mezcla de seres, que daba como resultado un animal quimérico, había que añadir que el horrendo animal era inmune a las balas y que su caza supuso la muerte de 20 hombres de una sola zarpada, por lo que hizo falta un Regimiento de Caballería y otro de Infantería para abatir al mencionado animal, no sin dificultades.

La noticia de este monstruo se hizo especialmente popular, según cuenta Zárate y Flores, no sólo por el hecho en sí sino por la polémica en la que se vio envuelto su editor, quien tuvo la necesidad de ofrecer determinadas explicaciones en el número posterior a la noticia del monstruo. Al parecer, a sus manos llegó la noticia de que en el

34 Diario noticioso universal, $\mathrm{N}^{\mathrm{o}}$ 1780. 2 de Septiembre de 1766, p. 3554.

35 Diario noticioso universal, $\mathrm{N}^{\mathrm{o}} 1082.19$ de Abril de 1765, p. 2163.

36 Correo mercantil de España y sus Indias. № 42.25 de Mayo de 1807, p. 331.

37 Diario noticioso universal, No $^{\circ} 1526.22$ de Octubre de 1765, p. 3049.

38 Numerosos ejemplos en ASUA, Miguel de y FRENCH, Roger: A New World on Animals, Aldershot, Ashgate, 2005.

39 Gazeta de México. № 28. 24 de Marzo de 1789. pp. 274 y ss. 
Diario Histórico, Político y Moral del P. Fr. Joseph de la Fuente, se refería la aparición de dicho monstruo en el año de 1725, del cual se había hecho una relación publicada en Madrid al año siguiente. Ante tal coincidencia, el editor declaró que su papel no era averiguar si el monstruo había revivido después de tantos años y agregó que jamás había salido por fiador de la noticia ${ }^{40}$.

\section{Monstruos carentes de brazos o piernas o de ambos}

Las noticias de personas que carecían de algún miembro superior o inferior o de ambos eran especialmente populares en los periódicos del siglo XVIII, y más que ser mostrados bajo el halo de un interés científico, eran mostrados como seres que despertaban la curiosidad, e incluso la admiración de los lectores. Y es que, lo que más resaltaba en este tipo de noticias era la pericia que tenían estas personas de sobrevivir y de mostrarse habilidosas en determinadas actividades que, en circunstancias normales, requerirían de ambas manos o piernas. Por otro lado, se hacía hincapié en la manera que éstos tenían de ganarse la vida exhibiéndose -bien ellos mismos, bien por medio de alguien- de manera lucrativa. Así, por ejemplo, para el primer caso nos encontramos con una noticia en el Memorial literario referida a una niña que "careciendo enteramente de brazos desde su nacimiento parte el pan y la tortilla con los dedos de los pies y con ellos se persigna, come y se peina como lo pudiera hacer con las manos" ${ }^{\prime 4}$. Asimismo, en la Gazeta de México se recogía la siguiente noticia:"... se halla un hombre llamado Josef Francisco de Salas, de quarenta años de edad, faltanle desde su nacimiento las manos y los pies; pero esto no le embaraza para escribir, ensartar una abuja, coser, andar, subir y baxar escaleras, comer con cubierto y usar de las demás funciones naturales sin dependencia de otro: cultiva por sí mismo una Huerta, y su principal exercicio es el de Maestro de Escuela, donde también azota á los muchachos"42.

Con respecto a la exhibición cabe destacar el caso del que se hace mención en la Gazeta de México de un niño exhibido por su padre: “...mestizo nació sin brazos, sin mas que una corta señal de ellos, con el pie izquierdo toma con la mayor facilidad lo que le dan, aunque sea cosa menuda como es un medio real, se persigna con la mayor perfeccion, se quita y se pone el sombrero con facilidad y garbo [...] Anda por los Lugares acompañado por su padre, que lo pasan muy bien con las limosnas que recojen, por la novedad que a todos causan" 43 .

\section{Monstruos bicorpóreos y bicípites}

Los monstruos bicorpóreos y bicípites llegaron a ser tan comunes en los tratados de teratología y tratados médicos, así como en las relaciones, avisos y periódicos, que no era de extrañar que un escritor afirmara en el Correo literario y económico de Sevilla que "ciertamente que no son muy raros los monstruos de esta especie, pues apenas hay autor que trate de la materia que no haga relación de muchos"44. Y es que, si algún monstruo acaparó la atención de médicos, cirujanos, teólogos, juristas y, por supuesto, curiosos ese fue el monstruo bicípite, por muchas de las dificultades que éste generaba

40 ZÁRATE, Verónica y FLORES, Eduardo: op. cit., pp. 270-271.

41 Memorial Literario $\mathrm{N}^{\mathrm{O}} \mathrm{XXVII.}$

42 Gazeta de México. № 6. 15 de Marzo de 1784, p. 52.

43 Gazeta de México. №37. 19 de Junio de 1787, pp. 370-371.

44 Correo literario y económico de Sevilla. No 101.15 de Septiembre de 1804, p. 244. 
en diferentes campos. En el caso de la prensa, resulta curioso el hecho de que mostrara las mismas preocupaciones que en el pasado mostraron los autores de teratologías o los manuales de confesores, ésas eran las de saber dónde residía el alma -cabeza o corazón- y, por tanto, la de saber cómo administrarles el bautismo. El Diario de Madrid, que se mostraría fiel seguidor de Feijoo, lo tenía bastante claro puesto que "el eruditismo Padre Maestro D. Benito Geronimo Feijoo prueba muy bien de que entre la disputa, ó question sobre el quál es el miembro principalísimo del cuerpo humano, el corazón ó la cabeza, se debe estar a favor de ésta, por muchas razones congruentes que expone" ${ }^{45}$. Asimismo, el autor de la noticia del Correo literario y económico de Sevilla remitiría a la obra de Feijoo por tratar en ella "el punto con quanta doctrina filosófica puede desearse, y aun teológicamente se expone lo que acerca del bautismo de semejantes monstruos puede ocurrir" 46 .

Sin embargo, no eran las cuestiones teológicas lo que más interesaba de los monstruos bicípites, sino las médicas y anatómicas. De ahí que en muchas de las noticias fueran descritos con amplia rigurosidad mediante el uso de términos médicos, y, asimismo se hacía hincapié en el examen que se les solía practicar tras su muerte. Así, por ejemplo, la Gazeta de México se hacía eco del fallecimiento de dos gemelos unidos y de cómo éstos pasaron a ser analizados por médicos y cirujanos: "Con este motivo [fallecimiento de los gemelos] el Alcalde Mayor de esta Ciudad convocó a los Médicos y Cirujanos de ella para la operación de esqueletarlos; y no pudiéndose conseguir, los dividieron y hallaron unidos los sesos con el intermedio de solo una tetilla sutil" ${ }^{47}$.

Se puede apreciar que el hecho de que los monstruos fueran analizados por cirujanos no partía de una iniciativa privada de éstos, sino de un interés público que implicaba, incluso, al alcalde mayor de una ciudad. La curiosidad médica por estos seres llegaba a tal punto que no se dudaba a la hora de ofrecer toda una descripción minuciosa de los mismos. Ya hemos relatado, por ejemplo, el caso de los niños de Francisca Duval cuya noticia ofrecía una exhaustiva descripción de la apariencia externa, interna y esquelética del ser bicípite, sin embargo, noticias de esta índole serían comunes en los diferentes periódicos tal y como podemos observar en la Gazeta de México del año 1793 donde se informa del nacimiento de dos niñas bicorpóreas el 25 de Noviembre de 1793. En ella se relata que la madre, una joven primeriza casada con un indio, después de unos terribles dolores de parto había dado a luz a "un monstruo vicorporeo, compuesto de dos hembritas unidas por los pechos"48. Tras la exhibición pública de éstas -intuimos, aunque no se indica en la noticia, que murieron al nacer- los facultativos deciden hacer una “inspección”, es decir, una especie de autopsia al ser bicorpóreo. La curiosidad por parte de los facultativos era de tal magnitud que no hay detalle que no aparezca en la noticia, así por ejemplo, en relación el corazón podía leerse lo siguiente:““...cuyo centro ocupaban un solo corazón de figura casi de un triángulo equilátero de 11 líneas de punta à punta de su base, y 10 del centro de esta al cono, cuyas superficies planas miraban al cartílago del arco: constaba de tres ventrículos y ocho vasos; uno común amplio que ocupaba quasi toda la superficie, que recibía las dos cavas de ambos cuerpos, y daban

45 Diario de Madrid. № 150. 30 de Mayo de 1793, p. 625.

46 Correo literario y económico de Sevilla. $\mathrm{N}^{\mathrm{o}}$ 101. 15 de Septiembre de 1804, p. 245.

47 Gazeta de México. №35. 19 de Abril de 1785, p. 282.

48 Gazeta de México. N ${ }^{\circ} 74.30$ de Diciembre de 1793, pp. 709 y ss. 
las dos arterias pulmonarias..." ${ }^{49}$. Y así, hasta casi una página entera. Asimismo, el autor de la noticia se mostraría tan interesado en relación a los seres bicorpóreos que no dudaría en recoger otros casos de seres similares que, al contrario que estas niñas, sí que sobrevivirían durante un largo periodo de tiempo.

Cabe mencionar que lo seres bicorpóreos y bicípites llegaron a ser no sólo objeto de interés público, sino también objetos de coleccionismo para los gabinetes de historia natural, tal y como se indica en el Mercurio de España en relación al nacimiento de un "monstruo biforme" el cual, tras el consentimiento del rey de España, fue colocado "entre las demás preciosidades del Gabinete de Historia Natural"50.

\section{Gigantes y enanos}

Al contrario de lo que pasó con el resto de razas monstruosas, tales cinocéfalos, amazonas, o esciápodos, etc., los gigantes y enanos seguirían estando presentes en el mundo de la teratología del siglo XVIII. Esto era debido, probablemente, por el hecho de que ver a un gigante o a un enano no era algo imposible como ver a una amazona o a un cinocéfalo. De ahí que noticias sobre éstos aparecieran en los periódicos dieciochescos.

En relación a los gigantes, la mayor parte de las noticias hacían hincapié a la capacidad de éstos por exhibirse. Ya recogíamos a principios del capítulo los anuncios de dos hombres gigantescos que se exhibían por la capital de España por un módico precio. La anormal estatura de éstos y el interés que provocaban entre el público ávido de maravillas y monstruosidades, les permitía ganarse la vida convirtiéndose en atracciones de ferias y circo. Noticias de exhibiciones de gigantes se repetirían también en los Anales de las Ciencias Naturales donde se recoge la historia de Martín Antonio Salmerón cuya "asombrosa y descomunal estatura [...] le ha hecho vagar de un modo lucrativo y nada común á los viajeros [...] por las diversas provincias de todo el Reyno Mexicano" 51 . Era tal la curiosidad que despertaba la altura de este hombre que el periódico, con el fin de satisfacerla a quien no lo había visto, decidió tomar sus medidas de que resultó lo siguiente: "su estatura de dos varas, dos tercias, una pulgada y siete líneas,; el espacio que media de uno á otro hombro mide dos tercias y una pulgada; de la palma de la mano á la extremidad de los dedos cuenta once pulgadas y tiene el pie otras catorce" ${ }^{52}$.

Ofreciendo estos datos, el periódico se convertía en un medio de exhibición en sí mismo para aquellos que, por diversos motivos, no habían podido acercarse a ver tal espectáculo. Sin embargo, la información proporcionada no quedaba reducida a las medidas sino que, además, el editor facilitaba más detalles del mencionado gigante como su poco apetito a pesar de su descomunal tamaño, su genio amable y su temperamento pacífico propios de una educación rural. Pero el editor va más allá y se atreve a teorizar sobre la temprana muerte del gigante usando como justificación la cita de Francis Bacon: "que quanto mas se retarde el incremento del hombre, tanto mayor será su duración [la vida]"53.

Muy relacionados con los gigantes estaban los patagones, aquellos seres de estatura descomunal que fueron situados en Sudamérica, especialmente en Tierra del Fuego. La 
cuestión sobre su existencia o no, había motivado a un autor a escribir una carta sobre el asunto en el Espíritu de los mejores diarios literarios....donde se preguntaba: “¿Es cierto que hay patagones, ó debe confundirse la historia de su existencia con la de los gigantes de la fábula?" 54 . Sin embargo, aunque el autor muestra que su veracidad no puede demostrarse con hechos debido a la cantidad de noticias maravillosas con las que los cronistas habían llenado sus obras, finalmente reconoce que su existencia" no presenta un fenómeno cuya realidad implique contradicción" ${ }^{55}$. Por lo que se puede extraer que, aunque dudoso, el autor admitía la posibilidad de que en algún lugar remoto del sur de Suramérica era posible que vivieran seres como los patagones, y acompañaba su idea con una serie de relatos recogidos por Garcilaso o Francis Drake donde se hablaban de las costumbres de estos gigantes, aunque ya en el siglo XVIII se encontraba muy extendida la opinión del carácter mítico de esta creencia ${ }^{56}$.

Por lo que respecta a los enanos, resulta curioso que lo que más llamara la atención fuera la proporcionalidad de sus miembros a pesar de su pequeñez. Tal perfección en la proporción del cuerpo se indicaba en la noticia del fallecimiento de un enano de 90 años en el Memorial literario: "El dia 13 del mismo mes de Febrero de 1784 falleció [...] un enano de 90 años, de poco mas de una vara de alto, perfecto en todas las partes de su cuerpo, y de robustez extraordinaria para su edad"57 En otra noticia recogida en ese mismo periódico, no era la proporción lo que más destacaba en el enano sino su "figura tan simétrica en medio de su deformidad" 58 . Y es que el autor de esta noticia relata con gran asombro cómo en Batavia, en las Indias Orientales Holandesas, había un hombre de reducido tamaño que mostraba una total simetría en su cuerpo, lo que lo había convertido en un extraño fenómeno. Sin embargo, esta deformidad que tan curiosa le resultaba al autor de la relación no fue tan interesante para la madre: "contaba que avergonzada su madre de haber dado á luz a un niño tan deforme, formó el proyecto de matarle, y cuando iba á executar su barbaro intento halló con gran sorpresa suya que era absolutamente invulnerable, y que este caso milagroso la hizo entrar en si misma, y dar oídos a los sentimientos naturales" $" 59$. No debe sorprendernos este intento de infanticidio por parte de su progenitora, ya que en siglos pasados, debido al miedo que el ser monstruoso suponía por ser considerado señal de un mal augurio, el infanticidio era una de las opciones que los padres barajaban tras el nacimiento de la criatura deforme ${ }^{60}$. Sí sorprende, quizás, que en este caso el infanticidio no esté motivado por el miedo sino más bien por la repugnancia y la vergüenza de la madre.

Más interesante si cabe es la noticia recogida en la Gazeta de México donde se relata la costumbre de dar un enano como obsequio. Y es que en ella puede leerse cómo dos individuos habían decidido obsequiar al Virrey de México con un enano descrito como "verdaderamente monstruoso en su genero, pues constando su tamaño de vara, quarta

54 Espíritu de los mejores diarios literarios que se publican en Europa. № 233. 17 de Mayo de 1790, pp. 60 y ss.

55 Ibídem.

56 Por ejemplo, en la Relación del último viaje al estrecho de Magallanes de la fragata de S.M. Santa María la Cabeza en los años de 1785 y 1786, Madrid, Viuda de Ibarra, 1788, pp. 322 y ss.

57 Memorial literario, instructivo y curioso de la corte. $\mathrm{N}^{\circ} 27$. Marzo de 1786, p. 338.

58 Memorial literario. $\mathrm{N}^{\circ} 27$, p. 289.

59 bídem, p. 290.

60 DEL RIO PARRA, Elena: Una era de monstruos: representaciones de lo deforme en el Siglo de Oro español, Madrid, ed. Iberoamericana, 2003, p. 64. SALAMANCA BALLESTEROS, A.: op. cit., pp. 85-90. 
y quatro dedos, guarda de medio cuerpo á arriba todas las proporciones de qualquier hombre de regular estatura" ${ }^{2}$. ¿Quedaba, por tanto, aún en el siglo XVIII restos de viejas costumbres como la de obsequiar enanos? ?2 $^{6}$. Es posible que así fuera y que los enanos fueran vistos más como mascotas ${ }^{63}$-como así fueron vistos en los siglos XVI y XVII- que como seres humanos con una discapacidad física.

\section{Hermafroditas y cambios de sexo}

Los hermafroditas fueron uno de los seres monstruosos más perseguidos durante el siglo XVIII ${ }^{64}$. La razón y la nueva forma de entender el género habían hecho que la existencia de hermafroditas se rechazara y que los "casos de sexualidad dudosa" se convirtieran más en un asunto de la medicina legal que de la teratología en sí mismo. Sin embargo, el nacimiento de un ser con doble sexo no dejaba de ser una noticia llamativa que debía de ser recogida por los periódicos, tal y como encontramos en el Espíritu de los mejores diarios literarios... donde puede leerse el examen que el propio editor del texto había hecho. El objeto de su observación era un joven llegado de Borgoña de una edad comprendida entre los 16 y los 17 años, y que había sido examinado en diversas academias -intuimos científicas- y sociedades particulares de Madrid. Según la descripción del propio autor, este "ser" presentaba: "miembro viril tiene la forma exterior que es ordinaria en un joven de su edad, excepto que no tiene abertura en su extremidad, y que se deve presumir carezca de conducto interior. [...] pero lo mas singular y lo que le da à este varon una falsa apariencia del sexo femenino, es que la división del escroto en parte diestra y siniestra, se efectua por una endidura de la longitud ordinaria de la bulba en la muger, y que casi tiene una pulgada de profundidad" 65 . No sólo su formación anatómica hacía que este ser tuviera una sexualidad ambigua, sino que -tal y como bien lo especifica el autor- el mismo había estado jugando con su propia sexualidad al vestir de mujer u hombre según su antojo ${ }^{66}$, cambios que podía realizar por su carencia

61 Gazeta de México. №6. 28 de Marzo de 1786, p. 80

62 Fernando Bouza explica en Locos, enanos y hombres de placer en la corte de los Austrias como Isabel Clara Eugenia, hija de Felipe II, regaló al enano Bonamí al recién nacido Felipe IV o cómo el enano Nicolasito fue regalado a Carlos II por el duque de Villahermosa. BOUZA ALVAREZ, F.: Locos, enanos y hombres de placer en la corte de los Austrias, Madrid, Ediciones Temas de Hoy, Colección Bolsitemas, 1996, pp. 51-52.

63 Johan Verberckmoes explica que el enano en la corte española jugaba un papel intermedio entre el mundo animal y el mundo humano, pues el enano era un ser situado entre el hombre y el animal de compañía. El enano llegaba a ser un confidente al mismo nivel que un animal doméstico. VERBERCKMOEAS, Johan: "Le monstre favor. Les nains à la cour des Archiducs Albert et Isabelle et dans le monde ibérique" en E. Stols, W. Thomas y J. Verbeckmoes, J.: op. cit., pp. 307-318.

64 Para el estudio de los hermafroditas en la Edad Moderna recomendamos CLEMINSON, R. y VAZQUEZ GARCÍA, F.: Hermaphrotidism. Medical science and sexual identity in Spain 1850-1960, Cardiff, University of Wale Press; CLEMINSON, R., y VÁZQUEZ GARCÍA, F.: "El destierro de lo maravilloso. Hermafroditas y mutantes sexuales en la España de la Ilustración" en Asclepio. Revista de Historia de la Medicina y de la Ciencia, vol. 62 (2010); VÁZQUEZ GARCÍA, F., y CLEMINSON, R.: "Subjetivities in transition: gender and sexual identities in cases of 'sex change' and 'hermafroditism' in Spain, c.1500-1800" en History of Science, Vol. 48, Part. 1, Number 159 (March 2010). pp. 1-38.

65 Espíritu de los mejores diarios literarios que se publican en Europa, № 144.1 de Septiembre de 1788, p. 331.

66 "usando este mozo ropas de mujer luego que llegó á París, hasta que desde algún tiempo à esta parte se ha empeñado en vestir como hombre" Ibídem, p. 332. Es importante recordar en este punto el hecho de que en el Antiguo Régimen, en ocasiones, el género no estaba vinculado a lo puramente biológico sino a lo social, se era hombre o mujer porque socialmente así se había establecido, y cambiar de sexo no suponía un cambio biológico sino social, es decir, se había producido un cambio de mujer a hombre porque se habían cambiado los estereotipos sociales. Es posible que este hecho estuviera vinculado con esta noticia y que no existiera una 
de barba y por el crecimiento de lo que se conoce por "monte de Venus". El examen de este hermafrodita hizo que el autor del artículo terminara planteándose dos preguntas: “¿Qué se deve pensar de la grande disputa de los Hermafroditas en la qual se han contado tantas fabulas? ¿Existen o no individuos en los que se hayan notado juntos, los caracteres distintivos de uno y otro sexo?"67.

Otro caso de hermafroditismo sería el recogido por el Mercurio Peruano en el año 1791, en el que se relata la noticia del alumbramiento de un monstruo por una negra bozal. Este monstruo poseía diversas deformidades, entre ellas la de carecer de cerebro y poseer "dos sexos: el viril situado debaxo del cordon umbilical, y casi confundiéndose con el, y el otro en su sitio natural" ${ }^{68}$. Sin embargo, el autor no mostraría interés alguno por el caso de hermafroditismo que se le presentaba, sino por la cuestión de la localización anatómica del alma ya que el ser monstruoso, al carecer totalmente de cerebro, suponía más un enigma "espiritual" para él que un objeto digno de interés médico-legal.

Al igual que ocurría con el hermafroditismo, los casos de cambios de sexo también daría lugar a interesantes reflexiones tal y como encontramos en uno de los periódicos donde se "trata si una mujer se puede convertir en hombre". El autor de esta relación, que presume de ser Profesor de Cirugía, explica a los lectores ávidos de curiosidad sobre el tema -“esta duda con que sorprenden las gentes en calles y plazas á los Profesores de Medicina y Cirugia" "99- debido a un caso que había tenido lugar en una monja $^{70}$, si era posible la famosa transmutación sexual. Éste, como buen recopilador de datos -cuya escritura recuerda más al de Antonio de Torquemada y su Jardín de flores curiosas - se limita a ofrecer una gran cantidad de opiniones de autores desde los clásicos (Tito Livio, Hipócrates) hasta Paulo Zaquías ${ }^{71}$. Asimismo, ofrece una detallada explicación con un vocabulario exclusivamente médico de las diferencias esenciales entre los hombres y las mujeres, concluyendo que es la gran magnitud del clítoris de la mujer lo que, en ocasiones, provocaba que se creyera en una posible transmutación sexual pero que ello no debía dar pie a que se consideraran a éstas como hermafroditas. El autor respaldaría su teoría con una serie de casos, asimismo concluiría la historia de la monja considerándolo un caso más de confusión provocado por el engrandecimiento del clítoris: "concluyo esta Disertacion diciendo, que si en la Monja de Granada no se hallan las circunstancias con que se diferencian específicamente los hombres de las mugeres, $[\ldots]$ no hay fundamento suficiente para reputarla por hombre ni menos por hermafrodita"72.

duplicidad sexual sino más bien social. Ver los trabajos citados de Cleminson y Vázquez.

67 Espíritu de los mejores diarios literarios que se publican en Europa, $\mathrm{N}^{\circ} 144.1$ de Septiembre de 1788, p. 332.

68 Mercurio Peruano, No 1.2 de Enero de 1791, p. 7.

69 Mercurio Peruano, $\mathrm{N}^{\circ} 167$ y 168, pp. 230 y ss.

70 La monja de la que se hace mención aparece también en la siguiente relación de suceso: Relacion verdadera de una carta que embio el padre Prior de la orden de santo Domingo, al Abad Mayor de San Salvador de la Ciudad de Granada, de un caso digno de ser avisado, como estuvo doze anos una monja professa, la qual avia metido su padre por ser cerrada, y no ser para casada, y un dia haciendo un exercicio de fuerça se le rompió una tela por donde le salió la naturaleza de hombre como los demás, y lo que se hizo para sacalla del convento: agora sucedido en este año de mil y seiscientos ydiez y siete. ETTINGHAUSEN, H. (ed.): op. cit. 71 Paulo Zaquías o Zacchias, médico del papa Inocencio X y autor de Questiones medico legales (1651). 72 Ibidem, p. 242. 


\section{Partos anormales y otras monstruosidades}

Como ya explicábamos al inicio de este trabajo, un parto podía considerarse también monstruoso, fuese por su duración, fuese por la multiplicidad del mismo ${ }^{73}$. En este caso, los nacimientos múltiples seguían siendo noticias curiosas con las que entretener al lector y que aparecían de manera constante. Al contrario de lo que pasaba en épocas anteriores, no eran considerados monstruosos pero sí llamaban la atención y se hacía notar que suponía un verdadero logro el que todas las criaturas sobrevivieran: "A las doce del 16 del próximo Julio nacieron de un parto en este Pueblo tres Criaturas, todas perfectamente formadas, y del tamaño regular que casa cada una de las que se nutren solas en el vientre materno el tiempo destinado por la Naturaleza. [...] No se sabe hasta ahora que haya muerto alguna"74 .

Más interesante, sin embargo, es otra noticia recogida en el Diario noticioso, curioso, erudito...: "Dícese, que en Macassar las mugeres paren frecuentemente un alligator o cocodrilo con una criatura. Un famoso comerciante digno de fe, que había venido de Macasar a Surata, nos confirmó este prodigio, asegurando, que de un tiempo se habían visto muchas de estas monstruosas producciones" 75 . Resulta curioso cómo el autor, que considera estas producciones como "monstruosas", detalla que los niños frutos de estos tipos de nacimientos no eran marginados o considerados monstruosos sino que eran objetos de un trato especial, pues se pensaba que hacían un gran servicio a la comunidad. Asimismo, indica que en algunos casos las mujeres de la isla de Célebes llegaban a criar a los cocodrilos como si fueran hijos suyos. Por tales motivos, estos partos en lugar de ser considerados como partos "accesorios" fruto de la putrefacción y algo monstruoso ${ }^{76}$, eran vistos como una situación normal en la que tanto el niño como el animal eran estimados.

Con respecto a los diferentes casos de monstruosidad, al ser considerada ésta como cualquier deformidad física por ínfima que fuese, los casos son muy numerosos y variados. Por ejemplo, podemos encontrar noticias relacionadas con niños que nacían con miembros desproporcionados: (nariz, cabeza, etc); con miembros multiplicados (tres lenguas, tres narices, etc), o con carencia de miembros (sin nariz, sin cerebro, o sin ojos). De hecho los niños cíclopes aparecerían en diversas ocasiones en la Gazeta de México, la primera de ellas el 14 de Julio de 1784 donde se ofrece el retrato de una criatura que había nacido con un único ojo en el centro de la cara.

Una segunda referencia a una criatura cíclope se haría el 8 de febrero de 1785 donde se anuncia el nacimiento de una niña que carecía de ojo derecho, además de tener una nariz deforme, carecer de boca y poseer seis dedos en cada mano y cada pie. Asimismo, el 18 de Agosto de 1802 nos encontramos con la noticia de que una joven india dio a luz a una niña con un solo ojo "redondo y mas grande de lo que era regular, el que mantuvo abierto y tremulo todo el rato que vivio"77.

73 Sobre este tema, la obra clásica es WILSON, Dudley: Signs and portents. Monstrous births from the Middle Ages to the Enlightenment, Londres/Nueva York, Routledge, 1993.

74 Gazeta de Mexico, № 19. 11 de Agosto de 1784, p. 129.

75 Diario noticioso universal. № 50328. 16 de Septiembre de 1775, p. 10588.

76 Salamanca Ballesteros trata el caso de los partos accesorios en su obra, op. cit., p. 249.

77 Gazeta de Mexico, No 16. 18 de agosto de 1802, p. 121. 
Otro caso, igualmente monstruoso y también recogido en la Gazeta de Mexico, es el del nacimiento de una niña que nació con unas "lenguas semejantes a la del loro"78. Esta monstruosidad despertó tal curiosidad que, una vez muerta la niña, se decidió exhibirla por el lugar para "constancia del hecho".

Este mismo periódico se hace eco del nacimiento de un niño descrito de la siguiente manera: "Parió una criatura con una carnosidad que le nacia de ambas sienes, mollera y ternilla de la nariz, con tres prominencias que de mayor á menor le nacían en su parte superior, colgándole á manera de moco de pavo ó guajolote, y cuya extremidad llegaba hasta el labio superior de su boca"79.

Por último, igualmente interesante es el caso de monstruosidad recogido en el $\mathrm{Mi}$ nerva o Revisor general donde se informa de la presentación en la Sociedad Médica de un niño extraordinario que era exhibido en el Paseo de Tourny bajo el nombre de "checrelas europeo". Su nombre se debía a la propia deformidad que el niño sufría, ya que según Buffon, este era el nombre que recibían los hombres que tenían la piel atigrada o manchada de otro color diferente al natural. Y es que, según se describe en la noticia, este niño de procedencia francesa tenía dos colores en su piel: "es negro hasta la cintura de los brazos y cuello; lo demás del cuerpo es blanco y sembrado de manchas negras de diferentes tamaños, y cubiertas de un pelo muy largo y espeso" ${ }^{\text {". Este tema }}$ sería muy recurrente, por cuanto ya lo encontramos en el siglo XVII, (como el caso de la niña mitad blanca y mitad negra nacida en Montilla en 1658) ${ }^{81}$, y reaparecerá en la prensa en repetidas ocasiones, tales en el Correo de Madrid del 26 de mayo de 1787, o el Diario de Madrid del 18 de agosto de 1786 y el 23 de abril de 1787.

\section{CONCLUSIÓN}

A lo largo del siglo XVIII, con el florecimiento de las publicaciones periódicas, la prensa se convierte en el principal medio informativo de todo tipo de sucesos, e incluso de los casos de monstruosidad. Su tratamiento, sin embargo, variará considerablemente del dado por anteriores publicaciones tales como Relaciones de sucesos, avisos e incluso tratados teratológicos, convirtiéndose en un fiel reflejo del cambio en la percepción de lo monstruoso. En sus páginas, las supersticiones que abundaban en épocas pasadas no tendrán cabida, dando paso a verdaderos análisis científicos del ser monstruoso, con el fin de poder entenderlos mejor y ofrecer causas verosímiles de su aparición. Por otro lado, se muestra cierta continuidad en determinados aspectos, como ese interés exhibicionista y morboso que se muestra hacia los monstruos, actitud que ni siquiera hoy día en el siglo XXI ha desaparecido, lo que de hecho se refleja en las frecuentes noticias de nacimientos de seres con deformidades fuera de lo común, o el interés por los siameses ${ }^{82}$.

78 Gazeta de Mexico, № 30. 19 de Mayo de 1795, p. 250

79 Gazeta de Mexico, № 86. 23 de diciembre de 1794, p. 709.

80 Minerva o El revisor general. Tomo VIII. 1807, p. 47.

81 DEL RIO PARRA, Elena, op. cit., p. 156.

82 Recientemente en la televisión inglesa, y española, se puede ver un programa llamado "Embarrasing bodies" donde trata precisamente de cuerpos con ciertas anomalías o deformidades de la que la persona se siente especialmente avergonzadas. Asimismo, en 2011, se publicó la noticia sobre el nacimiento de un niño nacido en China con dos cabezas, por no hablar de las adolescentes estadounidenses que grabaron un documental para explicar su día a día. Por tanto, las noticias actuales sobre "monstruos" siguen abundando. 
También se observa una continuidad en la tipología de los monstruos, y, aunque las razas monstruosas han desaparecido en gran medida con la excepción de enanos y gigantes, los cuales habría que preguntarse hasta qué punto pueden ser ya considerados como razas aparte, el resto de los monstruos citados no difiere mucho de los ya señalados en épocas anteriores, destacando, sobre todo, bicípites, hermafroditas, y partos monstruosos. Por lo que, aunque el conocimiento científico avanzara, y con ella la medicina, el ser monstruoso seguiría siendo visto como "anormal" y no como un ser con discapacidad física, tal como sería visto en épocas posteriores. El siglo XVIII se encuentra en un momento intermedio, el del tránsito del monstruo como anormalidad de la naturaleza a ser un ser con discapacidad física que requiere atención médica y cuidados especiales.

Por último, queda demostrada la importante función que tiene la prensa dieciochesca, no muy abordada por los modernistas ${ }^{83}$, como fuente de información para múltiples aspectos, entre ellos la teratología. Teratología que también nos informa acerca de las concepciones raciales (y racistas) de la época ${ }^{84}$, por cuanto, y no es casualidad, la incidencia de los seres monstruosos, y ello es algo que se percibe muy claramente en la prensa colonial, es mucho mayor en el seno de la población no europea. La supuesta superioridad social y cultural de los "blancos" se ve reforzada incluso desde el punto de vista médico, lo que no hace más que preludiar las creencias eugenésicas que tanto vigor tuvieron durante la tristemente conocida como la Europa negra ${ }^{85}$.

\footnotetext{
83 Existe una amplia bibliografía en torno al estudio de la prensa en la Edad Moderna, sin embargo, apenas algunas obras son escritas por historiadores. Cabría destacar las siguientes obras: BUTRON PRIDA, G.: "La prensa en Cadiz durante la etapa ilustrada 1763-1808", Estudios de historia social, 52-53, 1990; EGIDO LOPEZ, T.: Prensa clandestina española del siglo XVIII: el Duende Crítico, Valladolid, 1968, reed. 2001; ENCISO RECIO, L.M.: Nipho y el periodismo español del siglo XVIII, Valladolid, 1956; ENCISO RECIO, L.M.: Prensa económica del siglo XVIII: el Correo Mercantil de España y sus Indias, Valladolid, 1958; GARCIA HURTADO, Manuel Reyes: "La participación de los militares españoles en la prensa del siglo XVIII", Studia Historica, 32 (2010); GONZALEZ CRUZ, David: "Propaganda y fuentes de información en la prensa periódica de la América Hispana durante las guerras del siglo XVIII”, Obradoiro de Historia Moderna, 20 (2011). Sin embargo, sus temáticas se alejan a la aquí tratada. Sería conveniente resaltar otros trabajos cuyos autores no son historiadores pero que se consideran obras clásicas como: AGUILAR PIÑAL, F.: La prensa española en el siglo XVIII, Madrid, 1979; GUINARD, P.J.: La presse espagnole de 1737 á 1791, París, 1973; LARRIBA, E., Le public de la presse en Espagne a la fin du XVIIIe siecle, París, 1998.

84 Un repaso de las ideas raciales de la Ilustración en NOEL, Erick: Etre noir dans la France du XVIIIe siécle, París, 2006.

85 Vid. MARZOWER, Mark: La Europa negra, Barcelona, Ediciones B, 2001. El autor plantea de una forma magistral cómo las prácticas racistas y eugenésicas de los nazis, aunque éstos las llevaron a su máximo grado, estaban muy extendidas en el mundo occidental durante las décadas de 1920 y 1930.
} 


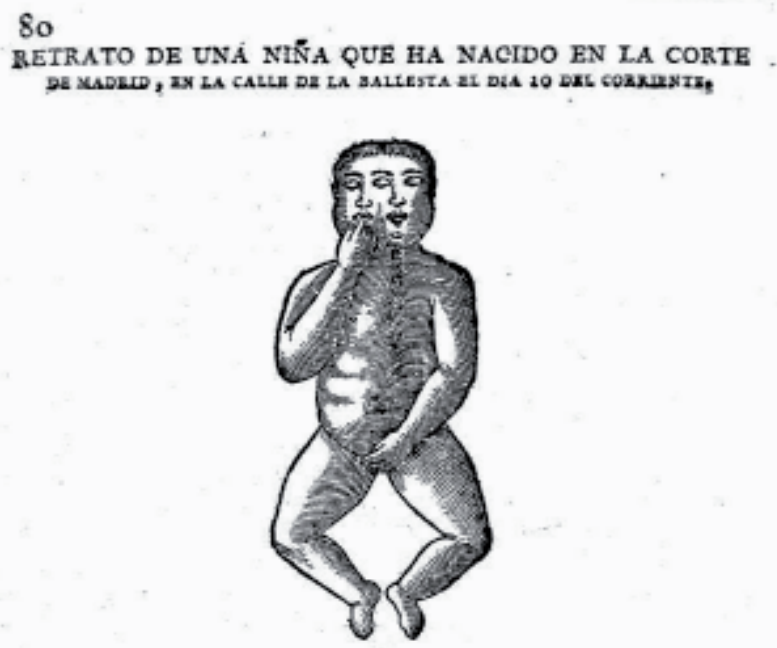

Ilustración 1- Niña bicípite. Diario de Valencia, 112, 20 de Octubre de 1790.

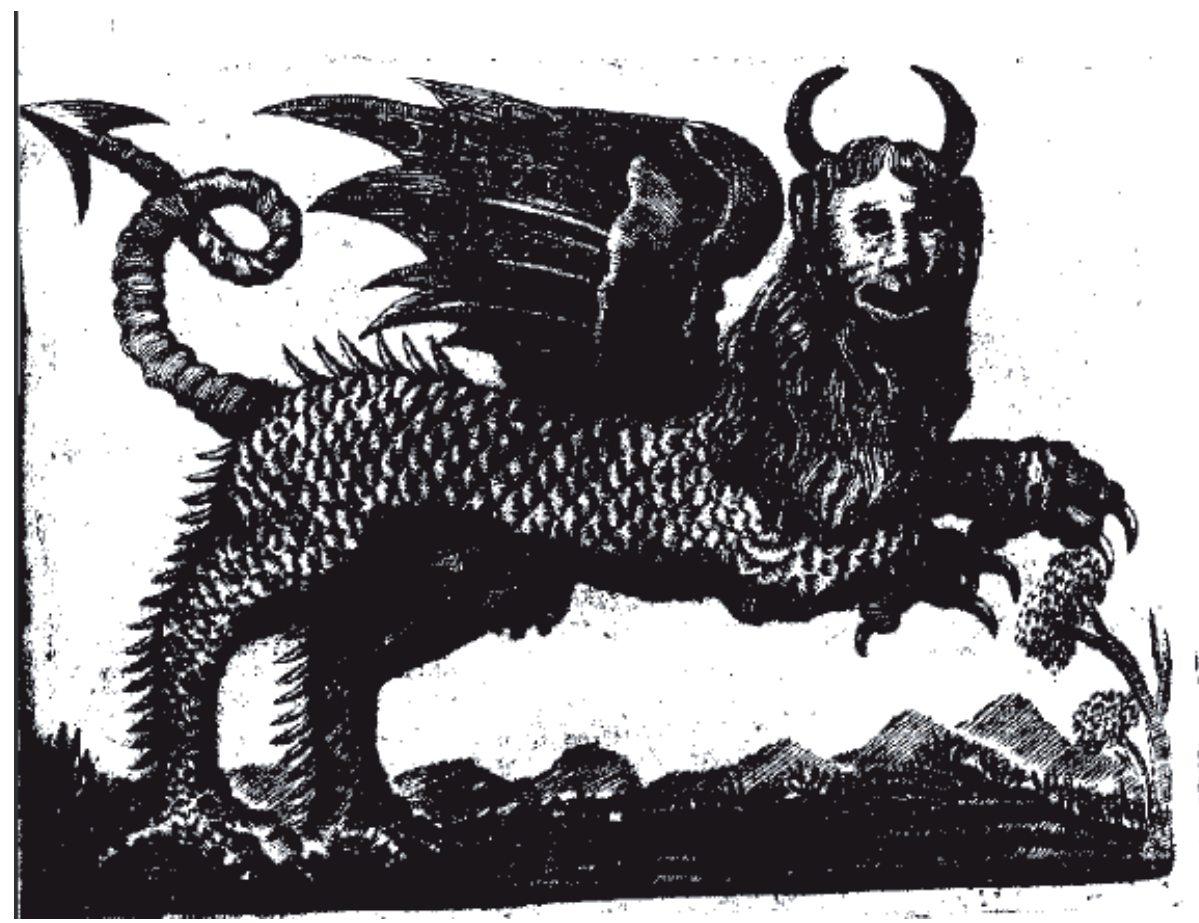

Ilustración 2- Monstruo de Jerusalén, Gazeta de México, 24 de Marzo de 1789. 


\section{AZET A DE MEXICI}

\section{DEL LUNES $3^{\circ}$ DE DICIEMBRE DE ×793.}

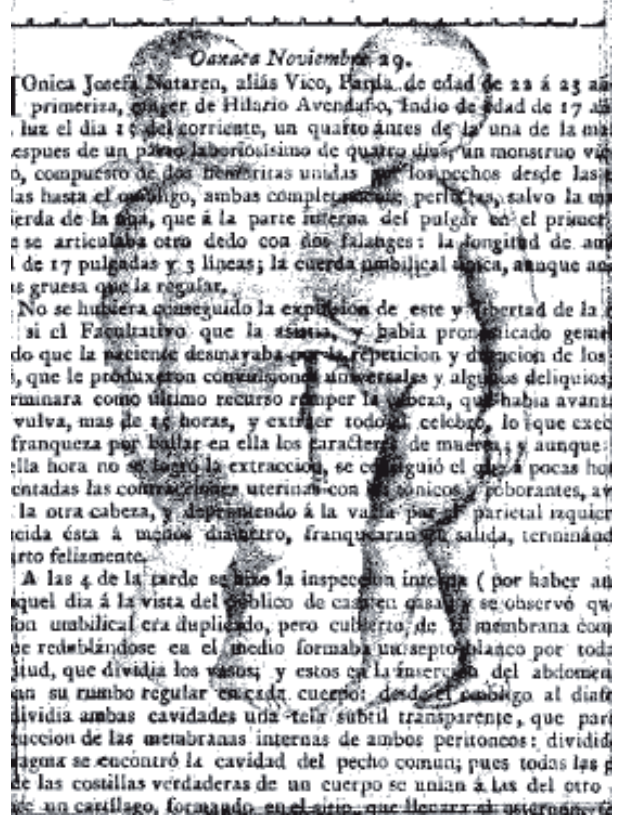

Ilustración 3- Imagen de las niñas bicorpóreas, Gazeta de México 31 de Diciembre de 1793.

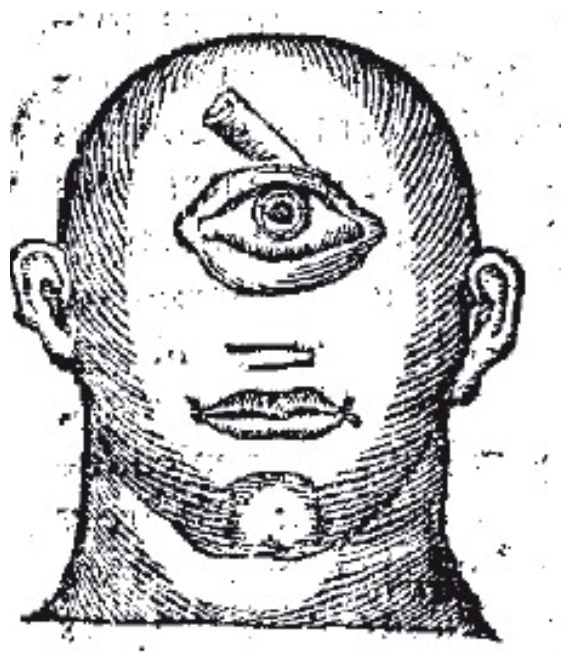

Ilustración 4- Retrato de la niña cíclope. Gazeta de Mexico, 14 de Julio de 1784. 


$$
\frac{19}{393}
$$

